\title{
Development of a novel TaqMan-based real-time PCR assay for the detection of porcine boca-like virus (Pbo-likeV)
}

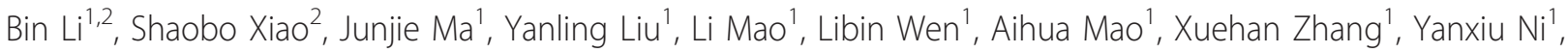
Rongli Guo', Junming Zhou', Zhengyu Yu', Lixin Lv', Xiaomin Wang ${ }^{1}$, Liurong Fang ${ }^{2}$, Huanchun Chen ${ }^{2}$ and Kongwang $\mathrm{He}^{1 *}$

\begin{abstract}
The recently discovered porcine boca-like virus (Pbo-likeV) is a member of the Parvoviridae family, genus Bocavirus, and it is potentially associated with swine disease. Several studies have associated Pbo-likeV with postweaning multisystemic wasting syndrome in pigs, but the full spectrum of clinical disease and the epidemiology of PbolikeV infection remain unclear. The availability of rapid and reliable molecular diagnostics would aid future studies of this novel virus. Thus, we developed a sensitive and specific TaqMan-based real-time PCR assay to target the Pbo-likeV NP1 gene. The assay reproducibly detected 20 copies of a recombinant DNA plasmid containing the NP1 gene, with a dynamic range of six orders of magnitude $\left(10^{2}-10^{7}\right.$ copies). The assay did not cross-react with other animal viruses. Clinical evaluation found that Pbo-likeV was present in Chinese swine herds at a frequency of $44.2 \%$ (114/258). Higher infection rates were found in diseased pigs $(56.1 \%, 101 / 180)$ compared with healthy pigs $(16.7 \%$, 13/78) $(P<0.05)$. Our assay for the diagnosis and quantification of Pbo-likeV was highly sensitive and specific, and should provide a reliable real-time tool for epidemiological and pathogenetic study of Pbo-likeV infection.
\end{abstract}

\section{Introduction}

Parvoviruses are members of the family Parvoviridae and can cause a broad spectrum of diseases in animals [1]. Based on their host range, the family Parvoviridae is classified into two subfamilies: the Parvovirinae subfamily infects vertebrates, while the Densovirinae subfamily infects arthropods. According to the International Committee on Taxonomy of Viruses (ICTV), and recent studies, the subfamily Parvovirinae can be divided into six genera: Parvovirus, Erythrovirus, Dependovirus, Amdovirus, Bocavirus, and a newly proposed genus, Hokovirus [2-5].

Bocaviruses are unique among parvoviruses in the subfamily Parvovirinae, which includes the bovine parvoviruses (BPV), canine minute viruses (CnMV), gorilla bocavirus (GBoV), and four species of human

\footnotetext{
* Correspondence: kwh2003@263.net

'Institute of Veterinary Medicine, Jiangsu Academy of Agricultural Sciences; Key Laboratory of Animal Diseases, Diagnostics, and Immunology, Ministry of Agriculture; National Center for Engineering Research of Veterinary Bioproducts, Nanjing 210014, Jiangsu Province, PR China

Full list of author information is available at the end of the article
}

bocaviruses (HBoV1-4) [1]. Bocaviruses contain a nonenveloped, autonomously replicating, single-stranded DNA virus genome, of approximately $5 \mathrm{~kb}[2,6-8]$. Like other members of the Parvoviridae family, bocaviruses contain the NS1 non-structural protein and the VP1/ VP2 structural protein. However, a non-structural NP1 protein encoded by an open reading frame (ORF) in the middle of the genome is a unique structure characterizing bocaviruses, which is absent in most Parvoviridae members [2].

In 2009, a novel porcine boca-like virus (Pbo-likeV) was discovered in Swedish pigs with postweaning multisystemic wasting syndrome (PMWS) using random amplification and large-scale sequencing technology [9]. Subsequent studies indicated a high prevalence of this novel Pbo-likeV was in weaning piglets with respiratory tract symptoms. Pbo-likeV has also been detected in healthy pigs in China $[10,11]$.

Pbo-likeV has not been successfully cultured and no serological tests are available, while only conventional PCR assays have been described [11]. In contrast to

\section{Biomed Central}


conventional assays, real-time PCR offers rapid results with potentially increased sensitivity and specificity of detection. It is also less prone to false positive results from amplicon contamination and is more amenable to the quantitative estimation of viral load. Here we report the development of a highly sensitive and specific TaqMan-based real-time PCR assay to target the NP1 gene for the rapid detection and quantitation of Pbo-likeV in clinical specimens.

\section{Materials and methods}

\section{Design of primers and probes}

Conserved regions of the Pbo-likeV NP1 genes were identified by nucleotide sequence alignments (GenBank: GU902967-GU902971, HQ223038, and FJ872544). Primers and TaqMan probes were designed using the Primer Express software (version 2.0; Applied Biosystems, USA) to generate a $77 \mathrm{bp}$ amplicon. The probe was labeled with 5-carboxyfluorescein (FAM) at the 5'-end and N, N, N', N'-tetramethyyl-6-carboxyrhodamine (TAMRA) at the 3 '-end. Primer and probe sequences are shown in Table 1.

\section{Construction of the plasmid DNA standard}

The full Pbo-likeV NP1 gene was amplified using the forward (5'-ATGAGTGGGCATCACAGCCACA-3') and the reverse primers (5'-TTATTTTCCAGCTTCAGCTTCTTGC-3') from a PCR-positive specimen. The product was cloned into the plasmid vector, pMD18-T (TaKaRa Biotechnology, Dalian, Japan) and verified by sequencing. The recombinant plasmid pMD18-NP1 was purified using a QIAamp mini-prep kit (Qiagen, Hilden, Germany) and quantified using an ND-1000 spectrophotometer (NanoDrop, Wilmington, DE, USA). Serial 10-fold dilutions of pMD18-NP1 were prepared in $10 \mathrm{mM}$ Tris-EDTA buffer ( $\mathrm{pH} \mathrm{8.0)}$ and stored at $-20^{\circ} \mathrm{C}$ prior to use in standard curve generation.

\section{Real-time PCR assay for Pbo-likeV}

The real-time PCR assay was performed in a $20 \mu \mathrm{L}$ reaction mixture containing $2 \mu \mathrm{L}$ extracted DNA or standard plasmid, $10 \mu \mathrm{L}$ TaqMan Universal PCR Master Mix (Applied Biosystems), $500 \mathrm{nM}$ each of forward and reverse primer, and $250 \mathrm{nM}$ of probe. Amplification and detection were performed with an ABI Prism 7500HT sequence detection system (Applied Biosystems) under the following conditions: uracil- $N$-glycosylase was activated at $50^{\circ} \mathrm{C}$ for $2 \mathrm{~min}$, followed by PCR activation at $95^{\circ} \mathrm{C}$ for $10 \mathrm{~min}$ and 45 cycles of amplification $(15 \mathrm{~s}$ at $95^{\circ} \mathrm{C}$ and $1 \mathrm{~min}$ at $60^{\circ} \mathrm{C}$ ). Analysis of each assay was conducted with Sequence Detector software (version 2.1; Applied Biosystems).

\section{Sensitivity of the real-time PCR}

To determine the detection limit and efficiency of the assay, standard plasmid DNA was used as a template and 10-fold serially diluted in $10 \mathrm{mM}$ Tris-EDTA buffer (pH 8.0) to produce $2.00 \times 10^{1}$ to $2.00 \times 10^{7}$ copies $\mu \mathrm{L}^{-}$ 1 . The sensitivity of the real-time PCR was compared with conventional PCR [11].

\section{Specificity and reproducibility of the real-time PCR}

Reactions with the positive-specimen template, different viruses (PRRSV, PCV2, PRV, CSFV, JEV, and PTTV), and negative controls (sterile water), were also performed to determine the specificity of the real-time PCR assay. Each intra- and inter-assay was performed in triplicate on three different days to evaluate reproducibility.

\section{Clinical specimens}

Clinical specimens were collected from different pig farms in China. The samples mainly included sera, lungs, lymph nodes, and tonsils of healthy and diseased pigs, especially weaning piglets with respiratory tract symptoms. Tissue samples were macerated and diluted 1:10 in Dulbecco's Modified Eagle Medium (DMEM), homogenized and centrifuged at $1500 \times g$ for $10 \mathrm{~min}$ to obtain a cell-free supernatant. All samples were stored at $-80^{\circ} \mathrm{C}$. Virus DNA was extracted from tissue homogenates (lymph node, tonsil, and lung) or sera using the QIAamp DNA Mini kit (Qiagen, Germany), according to the manufacturer's instructions.

\section{Results}

\section{Optimization of real-time PCR}

Optimization of the real-time PCR reaction components and cycling conditions was conducted using DNA standards and clinical samples with a known Pbo-likeV status. Nucleotide primers and $\mathrm{MgCl}_{2}$ were titrated to determine optimum concentrations and different

Table 1 Primers and probe used in real-time PCR assay for Pbo-likeV

\begin{tabular}{cccc}
\hline Gene & Primer-probe & Sequence & Position $^{\mathbf{a}^{2}}$ \\
\hline NP1 & Forward & 5 & $37-61$ \\
& Reverse & 5'TCGAGCTATACAACCGAAGAAGAGA-3' $^{\prime}$ & $93-113$ \\
& Probe & 5'TGTTCGGAGATGTCCTTGCT-3' $^{\prime}$ & $63-86$ \\
\hline
\end{tabular}

${ }^{a}$ Nucleotide position was designated according to NP1 gene of Pbo-likeV strain JSNJ1 (GenBank accession no. HQ872052) 
annealing and data acquisition temperatures were also evaluated (data not shown). The optimum conditions were defined as those that gave the maximum fluorescence and the lowest $\mathrm{Ct}$ values, in the absence of primer dimers or nonspecific amplification.

\section{Real-time PCR standard curve and dynamic range}

Ten-fold serial dilutions of plasmids were used to construct a standard curve by plotting the logarithm of the plasmid copy number against the measured $\mathrm{Ct}$ values (Figure 1). The standard curve had a wide dynamic range of $10^{2}-10^{7}$ copies $\mu \mathrm{L}^{-1}$ with a linear correlation $\left(R^{2}\right)$ of 0.995 between the $C t$ value and the logarithm of the plasmid copy number.

\section{Sensitivity of real-time PCR}

The sensitivity of the real-time PCR assay was evaluated by testing ten-fold serial dilutions of the DNA standards $\left(2.00 \times 10^{1}\right.$ to $2.00 \times 10^{7}$ copies $)$. Quantitative analysis identified a detection limit of approximately 20 copies of viral DNA (Figure 2).

\section{Specificity of real-time PCR}

The specificity of the TaqMan PCR assay was evaluated using eight different reactions, which included, PbolikeV, porcine reproductive and respiratory syndrome virus (PRRSV), porcine circovirus type 2 (PCV2), pseudorabies virus (PRV), classic swine fever virus (CSFV), Japanese encephalitis virus (JEV), porcine torque tenovirus (PTTV), and a water negative control. Strong fluorescent signals were obtained from reactions with Pbo-likeV, while the signals from six other porcine virus samples and the water control were equivalent to baseline levels under the optimized reaction conditions (Figure 3). Thus, Pbo-likeV was clearly differentiated

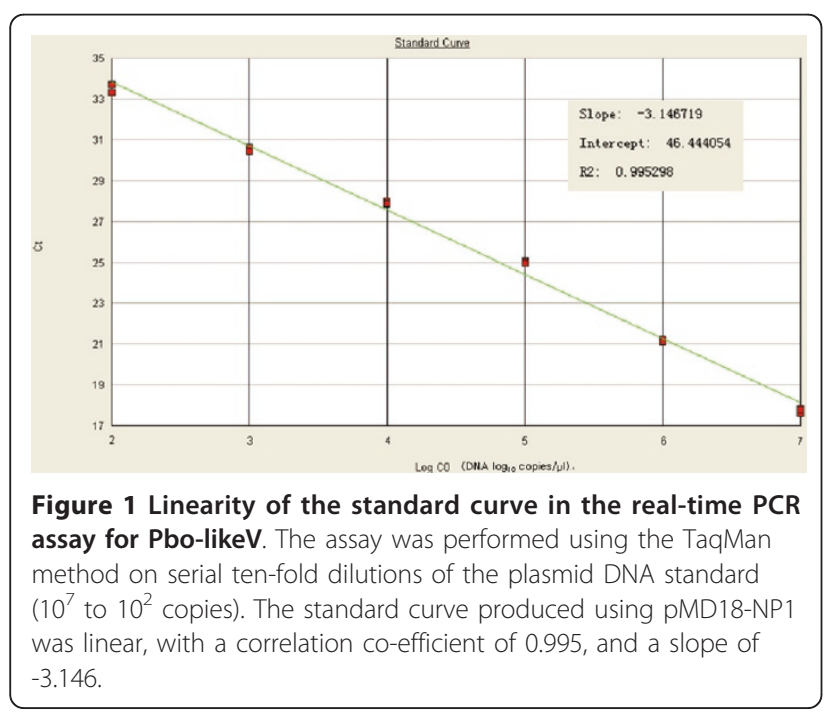

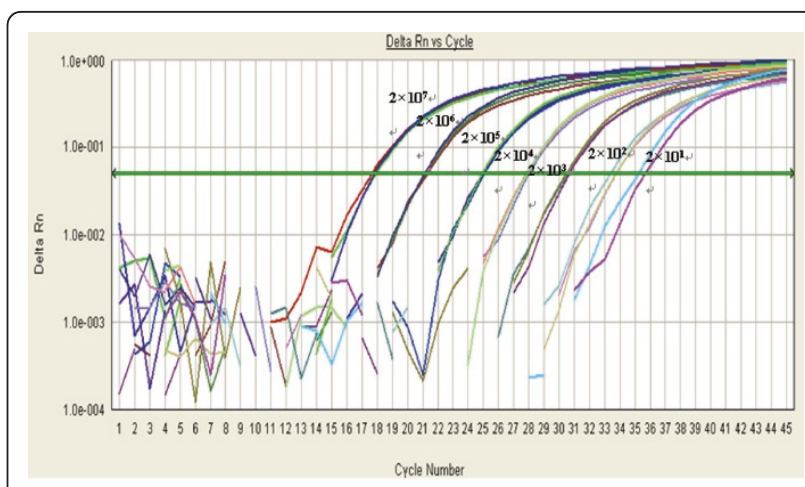

Figure 2 Sensitivity of the TaqMan real-time PCR assay for Pbo-likeV detection. Ten-fold dilutions of the standard template pMD18-NP1 containing the target nucleotide sequence were amplified using the real-time PCR assay. Amplification plots of 2.00 $\times 10^{7}$ to $2.00 \times 10^{1}$ copies/ $\mu \mathrm{L}$ of pMD18-NP1 were detected by real-time $P C R$ assay.

from other porcine viruses by comparing the signal strengths at different levels.

\section{Reproducibility of real-time PCR}

The intra- and inter-assay reproducibility was assessed using 10-fold serial dilutions of standard Pbo-likeV plasmid DNA ranging from $2.0 \times 10^{2}$ to $2.0 \times 10^{6}$ copies, in triplicate on three different days. Intra-assay variation ranged from 0.35 to $1.62 \%$, while and inter-assay variation ranged from 0.42 to $3.29 \%$, thereby indicating that the real-time PCR was highly reproducible (data not shown).

\section{Detection of Pbo-likeV in clinical samples by real-time PCR and conventional PCR}

Real-time PCR and conventional PCR were performed simultaneously on 258 clinical samples collected from several Chinese swine herds for diagnostic purposes. The results are summarized in Table 2 . The total positive frequency of Pbo-likeV in mainland China was $39.9 \%$ using conventional PCR. The positive frequency of Pbo-likeV $(51.7 \%, 93 / 180)$ in diseased and deceased

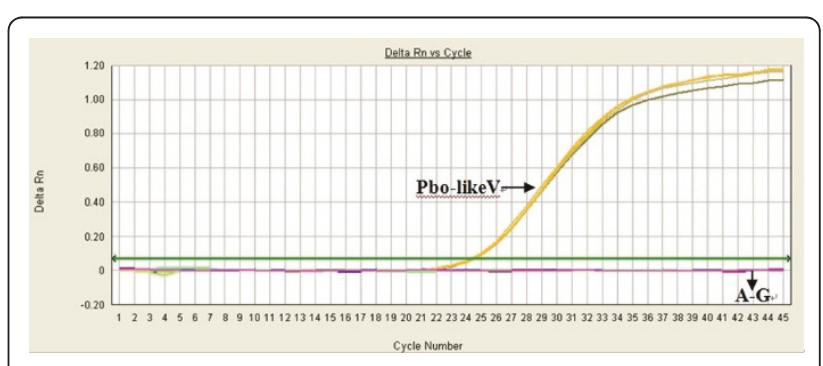

Figure 3 Specificity of the real-time PCR assay. Pbo-likeV: Positive sample; A-G: PRRSV, PCV2, CSFV, PRV, JEV, PTTV, and water control. 
Table 2 Detection of Pbo-likeV in pig samples using conventional PCR and TaqMan real-time PCR.

\begin{tabular}{|c|c|c|c|c|}
\hline \multirow[t]{2}{*}{ Animal } & \multirow[t]{2}{*}{ Health status } & \multirow[t]{2}{*}{ Type of tissue or samples } & \multicolumn{2}{|c|}{ No. positive/no. tested samples (\%) } \\
\hline & & & Conventional PCR & Real-time PCR \\
\hline & Healthy & Serum & $6 / 50(12.0)$ & $8 / 50(16.0)$ \\
\hline & & Tonsils & $4 / 28(14.3)$ & $5 / 28(17.9)$ \\
\hline & & Total & 10/78 (12.8) & $13 / 78(16.7)$ \\
\hline \multirow[t]{6}{*}{ Pigs } & $\begin{array}{c}\text { Diseased and } \\
\text { deceased }\end{array}$ & Serum & $57 / 110(51.8)$ & $61 / 110(55.5)$ \\
\hline & & Tonsils & $8 / 23(34.8)$ & 9/23 (39.1) \\
\hline & & Lymph & $6 / 11(54.5)$ & $6 / 11(54.5)$ \\
\hline & & Lung & $22 / 36(61.1)$ & $25 / 36(69.4)$ \\
\hline & & Total & $93 / 180(51.7)$ & $101 / 180(56.1)$ \\
\hline & All & Total & 103/258 (39.9) & $114 / 258(44.2)$ \\
\hline
\end{tabular}

pigs was significantly higher $(12.8 \%, 10 / 78)$ compared with healthy pigs $(P<0.05)$. The results showed that real-time PCR was more sensitive than the conventional PCR assay (Table 2). Furthermore, the positive frequency of Pbo-likeV with real-time PCR (44.2\%) was higher than that detected with conventional PCR (39.9\%). A high positive frequency of Pbo-likeV (56.1\%, $101 / 180$ ) was also detected in diseased and deceased pigs using real-time PCR. The highest frequencies were observed in lung (69.4\%) and lymph samples (54.5\%), which also had a high Pbo-likeV viral load (over $10^{5}$ copies $\mathrm{mg}^{-1}$ ). We also detected Pbo-likeV in tonsils, which had never been previously reported.

\section{Discussion}

Bocaviruses are emerging pathogens that cause various diseases in humans and animals. HBoV was first described in 2005 and it causes respiratory diseases in children [6]. However, the animal bocaviruses, CnMV and BPV, were discovered in the 1960s [12]. Pbo-likeV was discovered in 2009 in Swedish pigs with PMWS and it has a close relationship to bocaviruses $[9,13,14]$. A high prevalence (38.7\%) of Pbo-likeV was subsequently associated with PMWS in China [11]. Furthermore, PbolikeV was detected in pigs with and without PMWS, with infection rates of $88 \%$ and $46 \%$, respectively [10]. Thus, the new Pbo-likeV, and its possible role in swine disease, is currently under intensive investigation.

Methods for the detection of bocaviruses have relied on qualitative, rather than quantitative PCR, which limits the interpretation of results and slows down sample screening. There is an urgent need for rapid and sensitive detection and quantitation assays for Pbo-likeV, both in the pig industry and the research community. In this study, we developed a real-time PCR assay that targets the NP1 gene in the detection of Pbo-likeV. The NP1 gene is highly conserved in bocaviruses, and it is used a as detection target for $\mathrm{HBoV}$ [15]. Our assay provides a sensitive (approximately 20 copies) and specific diagnostic tool to allow quantification of Pbo-likeV in clinical specimens. The assay was performed over a wide dynamic range with low intra- and inter-assay variation, and showed no cross-reactivity with other animal viruses. Furthermore, the sensitivity of real-time PCR was significantly higher than that found in conventional PCR assays.

Our investigation of clinical samples indicated that Pbo-likeV was present in Chinese swine herds at a frequency of $44.2 \%(114 / 258)$, while higher infection rates were found in diseased pigs $(56.1 \%, 101 / 180)$ compared with healthy pigs $(16.7 \%, 13 / 78)(P<0.05)$. We also showed that the Pbo-likeV was more common in PMWS-affected pigs. However, the prevalence of PbolikeV in these pigs was lower than that reported previously [10]. The possible reasons for this are as follows. 1) The number of samples was limited. 2) The clinical samples were collected from pigs of all ages, although previous studies found that Pbo-likeV infection rates were low in adult sows and aborted fetuses, whereas weaning piglets were susceptible to infection with PbolikeV. 3) Zhai et al. [11] detected a seasonal prevalence of Pbo-likeV in swine herds, whereas we collected clinical samples throughout the year.

Pbo-likeV was also usually detected in diseased animals with co-infecting viruses (9-11) and additional studies are required to investigate the presence of PbolikeV in pigs and its possible role in PMWS.

\section{Conclusions}

The TaqMan real-time PCR assay described here was a rapid, sensitive, specific, and reproducible method for the detection and quantification of Pbo-likeV. This assay should provide a useful tool for analyzing the clinical and molecular epidemiology of Pbo-likeV infections in swine populations. 


\section{Acknowledgements}

This work was supported by the Special Fund for Independent innovation of Agricultural Science and Technology in Jiangsu province (CX (11) 4043 and cx (09) 619), the National High Technology Research and Development Program ("863" Project) of China (2011AA10A208) and National Natural Sciences Foundation of China $(31001066,31072155)$.

\section{Author details}

'Institute of Veterinary Medicine, Jiangsu Academy of Agricultural Sciences; Key Laboratory of Animal Diseases, Diagnostics, and Immunology, Ministry of Agriculture; National Center for Engineering Research of Veterinary Bioproducts, Nanjing 210014, Jiangsu Province, PR China. ${ }^{2}$ Division of Animal Infectious Diseases, State Key Laboratory of Agricultural Microbiology, College of Veterinary Medicine, Huazhong Agricultural University, Wuhan 430070, PR China.

\section{Authors' contributions}

LB was responsible for the study design, sampling, interpretation of data, and drafting the manuscript; SBX, JJM, YLL, LM, LBW, AHM, XHZ, YXN, RLG, $J M Z, Y Z Y, L X L, X M W, L R F, H C C$, and KWH contributed to experiments and drafting of the manuscript. All authors read and approved the final manuscript.

\section{Competing interests}

The authors declare that they have no competing interests.

Received: 28 January 2011 Accepted: 19 July 2011

Published: 19 July 2011

\section{References}

1. Claude M, Fauquet M, Maniloff J, Desselberger U, Ball LA: Virus Taxonomy: The Eighth Report of the International Committee on Taxonomy of Viruses, Academic Press. 2004

2. Manteufel J, Truyen U: Animal bocaviruses: a brief review. Intervirology 2008, 51:328-334.

3. Fauquet $C M$, Fargette D: International Committee on Taxonomy of Viruses and the 3,142 unassigned species. Virol I 2005, 2:64.

4. Lau SK, Woo PC, Tse H, Fu CT, Au WK, Chen XC, Tsoi HW, Tsang TH, Chan JS, et al: Identification of novel porcine and bovine parvoviruses closely related to human parvovirus 4. J Gen Virol 2008, 89:1840-1848.

5. Cheung AK, Wu G, Wang D, Bayles DO, Lager KM, Vincent AL: Identification and molecular cloning of a novel porcine parvovirus. Arch Virol 2010, 155:801-806.

6. Allander T, Tammi MT, Eriksson M, Bjerkner A, Tiveljung-Lindell A, Andersson B: Cloning of a human parvovirus by molecular screening of respiratory tract samples. Proc Natl Acad Sci USA 2005, 102:12891-12896.

7. Chen KC, Shull BC, Moses EA, Lederman M, Stout ER, Bates RC: Complete nucleotide sequence and genome organization of bovine parvovirus. J Virol 1986, 60:1085-1097.

8. Kapoor A, Mehta N, Esper F, Poljsak-Prijatelj M, Quan PL, Qaisar N, Delwart E, Lipkin WI: Identification and characterization of a new bocavirus species in gorillas. PLoS One 2010, 5:e11948.

9. Blomstrom AL, Belak S, Fossum C, McKillen J, Allan G, Wallgren P, Berg M: Detection of a novel porcine boca-like virus in the background of porcine circovirus type 2 induced postweaning multisystemic wasting syndrome. Virus Res 2009, 146:125-129.

10. Blomstrom AL, Belak S, Fossum C, Fuxler L, Wallgren P, Berg M: Studies of porcine circovirus type 2, porcine boca-like virus and torque teno virus indicate the presence of multiple viral infections in postweaning multisystemic wasting syndrome pigs. Virus Res 2010, 152:59-64.

11. Zhai SL, Yue C, Wei ZZ, Long JX, Ran DL, Lin T, Deng Y, Huang L, Sun LC, et al: High prevalence of a novel porcine bocavirus in weanling piglets with respiratory tract symptoms in China. Arch Virol 2010, 155:1313-1317.

12. Schwartz D, Green B, Carmichael LE, Parrish CR: The canine minute virus (minute virus of canines) is a distinct parvovirus that is most similar to bovine parvovirus. Virology 2002, 302:219-223.

13. Cheng WX, Li JS, Huang CP, Yao DP, Liu N, Cui SX, Yu Jin, Duan ZJ: Identification and nearly full-length genome characterization of novel porcine bocaviruses. PLOS ONE 2010, 5(10):e13583.
14. Zeng SL, Wang D, Fang LR, Ma J, Song T, Zhang RX, Chen HC, Xiao SB: Complete coding sequences and phylogenetic analysis of porcine bocavirus (PBoV). J Gen Virol 2011, 92:784-788.

15. Lu XY, Malinee OC, Mackay IM, Sloots TP, Fry AM, Erdman DD: Real-Time PCR assays for detection of bocavirus in human specimens. J Clin Microbiol 2006, 44:3231-3235.

\section{doi:10.1186/1743-422X-8-357}

Cite this article as: Li et al:: Development of a novel TaqMan-based real-time PCR assay for the detection of porcine boca-like virus (PbolikeV). Virology Journal 2011 8:357.

\section{Submit your next manuscript to BioMed Central and take full advantage of:}

- Convenient online submission

- Thorough peer review

- No space constraints or color figure charges

- Immediate publication on acceptance

- Inclusion in PubMed, CAS, Scopus and Google Scholar

- Research which is freely available for redistribution

Submit your manuscript at www.biomedcentral.com/submit
Ciomed Central 